\title{
Golgi Biogenesis
}

\author{
Yanzhuang Wang ${ }^{1}$ and Joachim Seemann ${ }^{2}$ \\ ${ }^{1}$ Department of Molecular, Cellular and Developmental Biology, University of Michigan, Ann Arbor, \\ Michigan 48109 \\ ${ }^{2}$ Department of Cell Biology, University of Texas Southwestern Medical Center, Dallas, Texas 75390 \\ Correspondence: yzwang@umich.edu and joachim.seemann@utsouthwestern.edu
}

The Golgi is an essential membrane-bound organelle in the secretary pathway of eukaryotic cells. In mammalian cells, the Golgi stacks are integrated into a continuous perinuclear ribbon, which poses a challenge for the daughter cells to inherit this membrane organelle during cell division. To facilitate proper partitioning, the mammalian Golgi ribbon is disassembled into vesicles in early mitosis. Following segregation into the daughter cells, a functional Golgi is reformed. Here we summarize our current understanding of the molecular mechanisms that control the mitotic Golgi disassembly and postmitotic reassembly cycle in mammalian cells.

\section{THE FUNCTION OF THE GOLGI}

$T_{\text {ellis }}^{\text {he }}$ he Golgi is a vital membrane-bound organelle found in all eukaryotic cells, including plants, animals, and fungi (Klute et al. 2011). Its basic structure is comprised of a stack of closely apposed and flattened cisternae with fenestrated rims. The primary function of the Golgi is to modify and package proteins and lipids into transport carriers and send them to the proper locations. Secretory or transmembrane proteins are delivered from the endoplasmic reticulum (ER) to the cis-Golgi network. Subsequently, the cargo molecules travel through the different cisternae of the Golgi where they are posttranslationally modified by resident enzymes. Modifications include glycosylation, phosphorylation, sulfation, and proteolysis (Goldfischer 1982). Cargo molecules have been described to move through the Golgi stack in several different ways (Emr et al. 2009). One possible mechanism is through cisternal maturation, in which the cargo remains in the cisternae and new cisternae form at the cis side. The newly formed cisternae then mature by receiving Golgi enzymes via retrograde transport of COPI vesicles (Bonfanti et al. 1998; Losev et al. 2006; Matsuura-Tokita et al. 2006). Alternatively, proteins are shuttled by COPI vesicles between cisternae, whereas Golgi resident enzymes reside in the relatively stable cisternal compartments (Orci et al. 1997; Elsner et al. 2003). In addition, cargo molecules may flow through transient tubular connections between adjacent cisternae (Trucco et al. 2004), or by rapid partitioning between different lipid domains (Patterson et al. 2008). At the transGolgi network (TGN), cargo molecules are sorted and transported to their proper destinations such as the endosomal-lysosomal system,

Editors: Graham Warren and James Rothman

Additional Perspectives on The Golgi available at www.cshperspectives.org

Copyright (C) 2011 Cold Spring Harbor Laboratory Press; all rights reserved; doi: 10.1101/cshperspect.a005330

Cite this article as Cold Spring Harb Perspect Biol 2011;3:a005330 
Y. Wang and J. Seemann

the plasma membrane, or outside of the cell. In addition to its function in protein trafficking, the Golgi in mammalian cells plays an important role in cell polarity (Jaffe and Hall 2005) and cell cycle control (Sutterlin et al. 2002), suggesting a direct link between membrane trafficking, cell growth, and cell polarity.

\section{The Structure of the Golgi in Different Organisms}

Although the most characteristic structure of the Golgi is the stack of closely aligned cisternal membranes, some species and specialized cell types show variations in the number and morphological organization of the stacks. In some unicellular eukaryotes, including Toxoplasma gondii (Hager et al. 1999), Trypanosoma brucei (He et al. 2004), and the green algae Ostreococcus tauri (one of the smallest free-living unicellular eukaryotes) (Henderson et al. 2007), each cell contains only one single Golgi stack. In the vast majority of organisms, including most fungi, plants, and invertebrates, each cell hosts multiple Golgi stacks that are scattered throughout the cytoplasm. However, several eukaryotic species do not seem to have a stacked Golgi (Dacks et al. 2003; Klute et al. 2011). One prominent example is the budding yeast Saccharomyces cerevisiae, in which Golgi membranes do not form stacks under normal growth conditions. Instead, individual cisternae are distributed throughout the cytoplasm (Preuss et al. 1992). Notably, Golgi cisternae appear to be stacked in certain mutant strains of S. cerevisiae (Novick et al. 1981; Franzusoff et al. 1991; Weinberger et al. 2005), but it is unclear whether the stacks show structural and functional cis-to-trans polarity as in most other species.

The fact that Golgi cisternae in S. cerevisiae are not aligned into stacks indicates that stacking is not essential for secretion. However, Golgi stacking is a pronounced feature of the majority of eukaryotic organisms (Mowbrey and Dacks 2009; Klute et al. 2011), suggesting that stacking has important functional consequences. Indeed, several lines of evidence indicate that stacking increases the complexity of Golgi function. Stacking of Golgi membranes impacts the rate of protein trafficking and the accuracy of its processing. The close spatial arrangement of cisternae in stacks minimizes the distance the molecules have to travel, which may improve the efficiency of cargo transport. By reducing the space between the cisternae, budding transport vesicles are already in close proximity to the target membrane with which they fuse (Linstedt 1999). Furthermore, during budding, local tethering complexes link the vesicles to the target cisternae, which may prevent the vesicles from diffusing away (Lupashin and Sztul 2005). Perhaps more importantly, cisternal stacking directly controls the flux rate of protein trafficking through the Golgi stack. The progression of molecules through the stack depends on the budding and fusion rate of COPI vesicles. With fully stacked cisternae, vesicles can only form and fuse at the rims. Once the cisternae unstack, however, more membrane area becomes accessible, thereby increasing the rate of vesicle budding and cargo transport through the Golgi (Wang et al. 2008). Moreover, stacking ensures efficient and accurate posttranslational modifications of cargo proteins by the resident glycosylation enzymes (Varki 1998). Each cisterna corresponds to a different reaction compartment, in which a specific subset of enzymes is concentrated. These enzymes are distributed across the stack in the order by which they operate (Kornfeld and Kornfeld 1985; Roth 2002). This ensures that the cargo proteins are modified sequentially and accurately as they travel through the stack.

Unlike the discrete individual stacks in lower organisms, the Golgi in vertebrate cells shows a more complex organization (Wei and Seemann 2010). Each mammalian cell typically contains about 40-100 Golgi stacks (Shima et al. 1998) that usually interconnect with each other into a continuous ribbon-like structure that is localized adjacent to the nucleus (Fig. 1A) (Rambourg et al. 1987). The formation and maintenance of the perinuclear localization of the Golgi ribbon relies on the well-organized microtubule cytoskeleton emanating from the perinuclear centrosomes (Glick and Nakano 2009). The minus end-directed motor cytoplasmic dynein associates with the 
Golgi Biogenesis
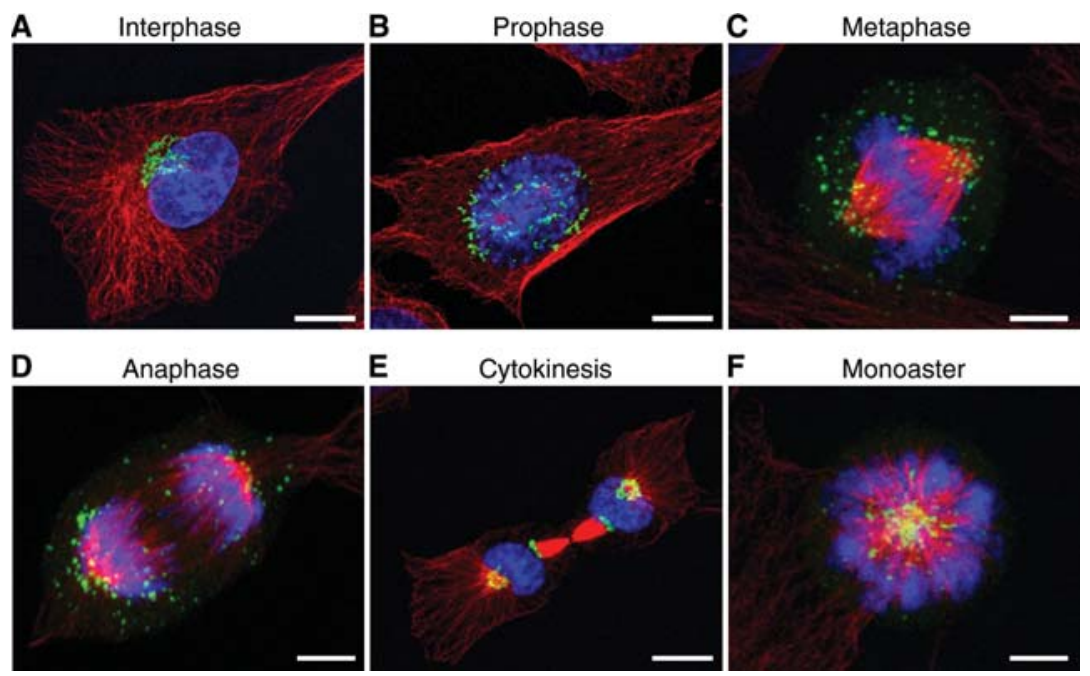

Figure 1. Morphology of the Golgi during the cell cycle in mammalian cells. Untreated NRK cells $(A-E)$ or cells treated with the kinesin 5 inhibitor s-trityl-L-cystein, that inhibits centrosome separation and thereby induces the formation of monoasters $(F)$, were fixed and triple-stained for the Golgi resident protein GM130 (green), $\alpha$-tubulin (red), and DNA (Hoechst, blue). Images are z-projections of confocal image stacks. The continuous Golgi ribbon $(A)$ is disassembled in early mitosis $(B)$. The Golgi membranes concentrate at the spindle poles in metaphase cells $(C)$ as well as in cells with monoasters $(F)$. During anaphase $(D)$, the Golgi membranes are partitioned and reform two ribbons on the opposite sides of the nucleus $(E)$. Scale bar $10 \mu \mathrm{m}(A, B, E) ; 5 \mu \mathrm{m}(C, D, F)$.

Golgi and moves the membranes along the microtubules toward the centrosomes, leading to the concentration of the Golgi stacks in the pericentriolar region and formation of the Golgi ribbon (Rios and Bornens 2003; Miller et al. 2009). The variations in Golgi architecture among species suggest that the molecular mechanisms that control the Golgi structure and its inheritance may have evolved differently. Here we focus on the mechanisms that facilitate the inheritance of the mammalian Golgi during mitosis.

\section{MOLECULAR MECHANISMS OF GOLGI BIOGENESIS IN MAMMALIAN CELLS}

In mammalian cells, the continuous Golgi ribbon needs to be segregated into the two daughter cells when the cell divides. This is achieved through a three-step process (Fig. 2) that involves disassembly (consisting of ribbon unlinking, cisternal unstacking, and vesiculation), partitioning, and reassembly of Golgi membranes (Wei and Seemann 2009b). In late G2 phase of the cell cycle, the Golgi ribbon is unlinked upon separation of the lateral connections between the stacks. In early mitosis, the cisternae then unstack and further disassemble into vesicular and tubular membranes (Lucocq et al. 1989). These mitotic Golgi membranes are then divided into the two daughter cells where they are reassembled into a functional Golgi (Shorter and Warren 2002; Lowe and Barr 2007).

\section{The Biological Significance of Mitotic Golgi Disassembly in Mammalian Cells}

Several lines of evidence indicate that the disassembly of the Golgi ribbon is important for its division process (Shorter and Warren 2002) as well as for mitotic progression (Colanzi and Corda 2007). The simplest explanation for mitotic Golgi disassembly is the necessity to divide the continuous ribbon between the two daughters. In support of this notion, the Golgi in some primitive organisms undergoes binary fission to split the organelle into two entities (Pelletier et al. 2002). The comparable process in mammalian cells is the unlinking of the Golgi 
Y. Wang and J. Seemann

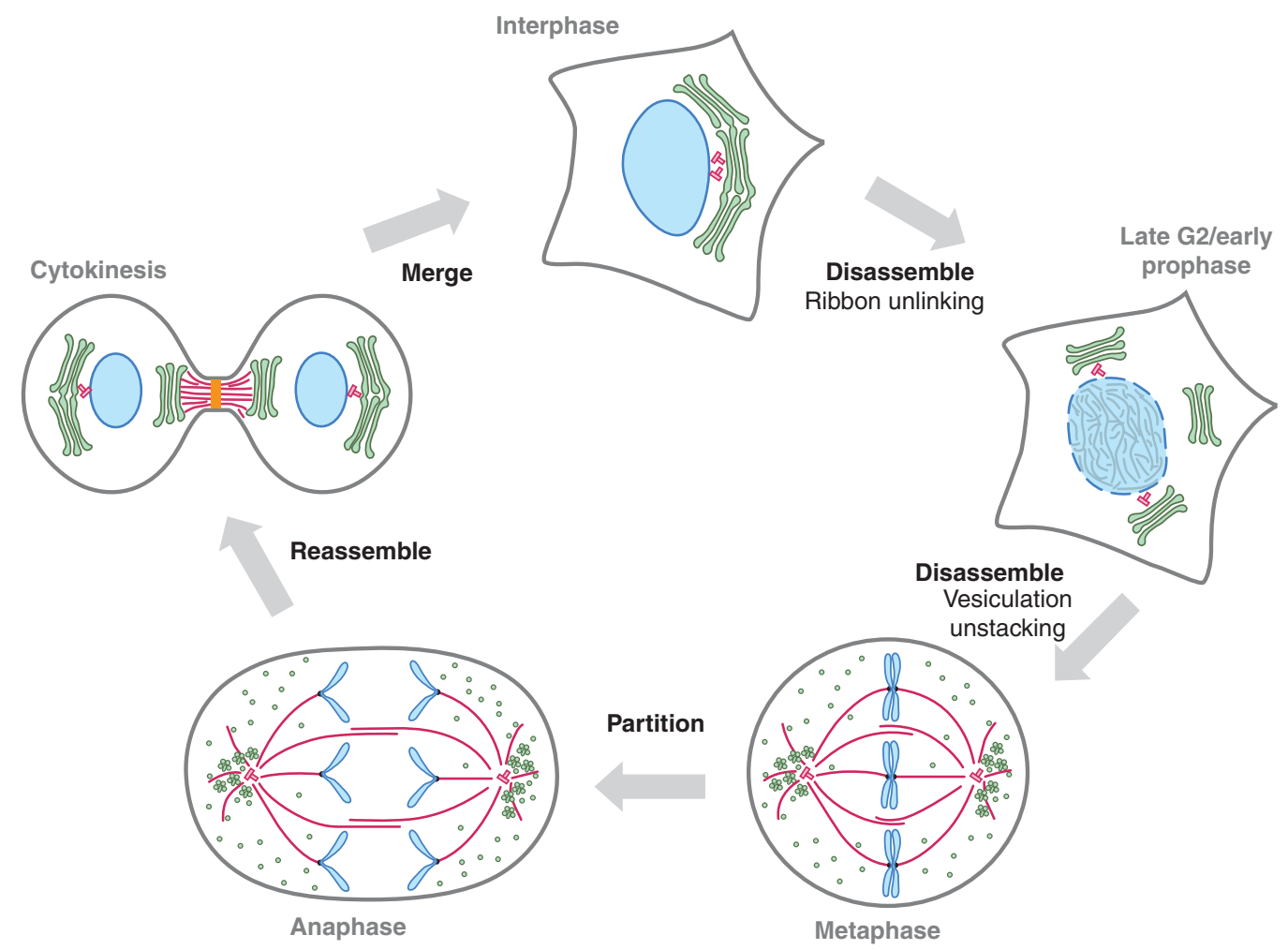

Figure 2. Schematic illustration of the mitotic division of the mammalian Golgi. During interphase, the Golgi stacks (green) are interconnected into a ribbon-like structure near the centrosomes (red) and next to the nucleus (blue). In late G2, before the cells enter mitosis, the connections between the stacks are severed. In early mitosis, the Golgi cisternae unstack and vesiculate, leading to the disassembly of the Golgi. By metaphase, mitotic Golgi membranes cluster at the spindle poles, associate with astral microtubules, and are dispersed throughout the cytoplasm. The membranes are then partitioned as the spindle elongates and segregates the chromosomes during anaphase. During telophase and cytokinesis, the Golgi membranes reassemble in each daughter cell into a larger ribbon next to the centrosome and a smaller ribbon adjacent to the cleavage furrow. In the final stage, the smaller ribbon moves to the opposite side of the nucleus to merge with the larger ribbon.

ribbon in late $\mathrm{G} 2$ phase. This first step in the disassembly process has been described to contribute to the transition between G2 and mitosis (Colanzi and Corda 2007). Inhibition of this step by interfering with a particular set of Golgi structural proteins (GRASP65 and GRASP55), kinases (MEK1, ERK, and Plk3), or membrane fission molecules (CtBP/BARS) delays G2/M transition. These observations led to the postulation of a Golgi-specific checkpoint (Sutterlin et al. 2002; Hidalgo Carcedo et al. 2004; Yoshimura et al. 2005; Colanzi et al. 2007; Feinstein and Linstedt 2007) that monitors the structural integrity of the Golgi ribbon and delays entry into mitosis, but differs from the conventional
G2/M DNA damage checkpoint. Inhibition of Golgi ribbon unlinking prevents a key mitotic regulator, the Aurora A kinase, from being recruited to the centrosomes and thus impairs its activation (Persico et al. 2010).

After the ribbon is unlinked and the cell enters mitosis, the Golgi cisternae are unstacked and converted into vesicular membranes. Complete vesiculation does not appear to be an absolute requirement for Golgi partitioning or mitotic progression. Expression of nonregulatable mutants of the Golgi stacking protein GRASP65 (Tang et al. 2010b) or microinjection of a nonphosphorylatable p47 (Uchiyama et al. 2003), an adaptor protein of the AAA ATPase 
p97 that is involved in postmitotic Golgi membrane fusion, leads to larger, less disassembled clusters of Golgi membranes during mitosis, but does not seem to block the segregation of Golgi membranes into the daughter cells. Instead, a more possible role for Golgi vesiculation may be to release components from the Golgi that have an important role in late mitosis or cytokinesis (Wei and Seemann 2010). For example, Nir2, a Golgi-associated protein in interphase, is released from the Golgi membrane in mitosis and moves to the cleavage furrow where it is required for cytokinesis (Litvak et al. 2004). In addition, the Golgi also provides membranes for the abscission step (Gromley et al. 2005; Goss and Toomre 2008).

\section{Mechanisms of Mitotic Golgi Disassembly \\ Unlinking the Golgi Ribbon}

In late $\mathrm{G} 2$ phase, the Golgi ribbon is unlinked by severing the tubular connections between the stacks (Colanzi and Corda 2007). The conversion of the ribbon into stacks depends on the MAP kinase, kinase MEK1 (Acharya et al. 1998; Colanzi et al. 2000; Kano et al. 2000; Sutterlin et al. 2001), but not the classical MEK1 substrates ERK1 or ERK2 (Acharya et al. 1998; Colanzi et al. 2000). Instead, ERK1c and Plk3/ VRK1 were shown to contribute to Golgi ribbon unlinking in late G2 phase (Xie et al. 2004; Shaul and Seger 2006; Lopez-Sanchez et al. 2009), but their substrates on the Golgi membranes have not yet been identified. Another study showed that MEK1 causes Golgi ribbon unlinking through mitotic phosphorylation of GRASP55 by ERK2 (Jesch et al. 2001a). Expression of a nonphosphorylatable GRASP55 mutant interferes with ribbon unlinking in late G2 (Feinstein and Linstedt 2008), although this result was not confirmed by others (Duran et al. 2008; Xiang and Wang 2010). Precisely how GRASP55 is involved in Golgi ribbon unlinking remains unclear. Similarly, microinjection of antibodies against GRASP65 also indicates a role for GRASP65 in severing of the ribbon (Puthenveedu et al. 2006) and the progression from G2 into M-phase (Sutterlin et al. 2002). Besides these kinases, the membrane fission protein
CtBP1/BARS is important for Golgi ribbon unlinking (Hidalgo Carcedo et al. 2004). Inhibition of BARS activity prevents severing of the ribbon as well as G2/M transition (Colanzi et al. 2007), but the underlying molecular mechanisms as well as the signaling events that activate BARS await further investigation.

\section{Vesiculation and Unstacking of the Cisternae}

Following the conversion of the Golgi ribbon into stacks, the cisternae are unstacked and vesiculated through COPI-dependent vesicle formation (Misteli and Warren 1994; Xiang et al. 2007; Tang et al. 2008). Vesiculation and cisternal unstacking occurs simultaneously in early mitosis, leading to rapid conversion of the Golgi into vesicular and tubular membranes. Vesiculation of the Golgi cisternae is triggered by an imbalance of membrane budding and fusion during mitosis (Warren 1993; Lowe et al. 1998b). In interphase, COPI vesicles are captured and tethered to the cis-cisternae by the ternary giantin-p115-GM130 tethering complex prior to membrane fusion (Fig. 3A) (Nakamura et al. 1997; Sonnichsen et al. 1998). Giantin on the vesicle is linked by p115 to GM130 on the Golgi cisternae (Nakamura 2010), which is regulated by the small GTPase Rab1 (Moyer et al. 2001; Weide et al. 2001; Beard et al. 2005). Once the complex is formed, p115 directly catalyzes the formation of SNARE complexes, leading to fusion of the two membranes (Shorter et al. 2002; Diao et al. 2008). During mitosis, Arf1 remains active and COPI vesicles continue to form (Xiang et al. 2007), but the vesicles cannot fuse with their target membranes because of the disruption of vesicle tethering complex (Misteli and Warren 1994; Nakamura et al. 1997; Lowe et al. 1998b). Phosphorylation of GM130 by Cdk1 in early mitosis prevents p115 from binding, thereby blocking vesicle tethering and subsequent fusion (Fig. 3B) (Levine et al. 1996; Lowe et al. 1998b). Rab1 is also phosphorylated by Cdk1, which may contribute to the inhibition of vesicle tethering and fusion (Bailly et al. 1991; Preisinger et al. 2005). The persistent budding of COPI vesicles without fusion 
Y. Wang and J. Seemann

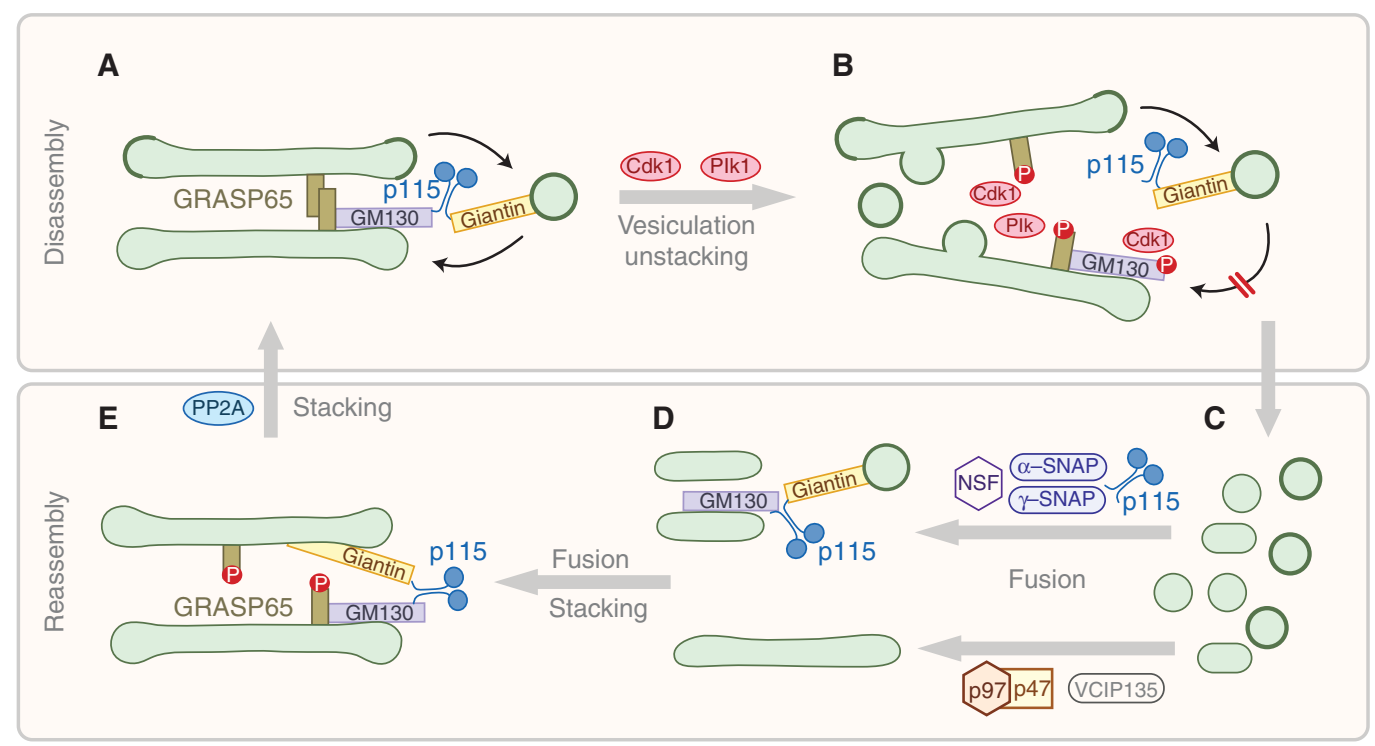

Figure 3. Schematic illustration of putative Golgi disassembly and reassembly mechanisms during the cell cycle. (A) During interphase, Golgi cisternae are held together by trans-oligomers of GRASP65 and GRASP55 (not shown). COPI transport vesicles are tethered to the Golgi by the giantin-p115-GM130 complex, which facilitates fusion with the targeting membrane. (B) Early in mitosis, phosphorylation of GM130 by Cdk1 inhibits binding of p115, which helps block vesicle tethering and subsequent fusion. GRASP65 is phosphorylated by Cdk1 and Plk, which disrupts GRASP65 oligomerization and results in cisternal unstacking. Unstacking increases the membrane surface for the formation of COPI vesicles that fail to fuse because of the disruption of the tethering complex, leading to disassembly of the Golgi $(C)$. (D) During late mitosis, the Golgi reforms by two fusion processes mediated by NSF and p97 ATPases together with their adaptor proteins. Following dephosphorylation of GM130, tethering and NSF-mediated fusion are restored, generating short cisternae, whereas p97-mediated fusion reassembles membranes into longer, but single cisternae. Reformed cisternae are first linked by p115 and then stacked once GRASP65 is dephosphorylated by PP2A.

gradually consumes the cisternae (Lowe et al. 1998a). In addition to COPI-dependent vesiculation, the Golgi cisternae are also disassembled by a COPI-independent pathway (Misteli and Warren 1995), but the exact role and mechanism of this pathway remains elusive.

Efficient disassembly of the Golgi in early mitosis is facilitated by unstacking of the cisternae, which significantly enhances COPI vesicle formation. Compared to stacked cisternae, unstacked membranes provide a larger surface for COPI vesicle budding (Fig. 3B) (Wang et al. 2008). Mitotic unstacking of Golgi cisternae is achieved through phosphorylation of GRASP65 and its homolog GRASP55. The GRASP proteins are Golgi peripheral membrane proteins that form dimers. These dimers from adjacent membranes interact with each other to form trans-oligomers that hold the Golgi cisternae together in a stack (Wang et al. 2003). Mitotic phosphorylation leads to GRASP deoligomerization and thus Golgi unstacking (Wang 2008). GRASP65 is regulated by the Polo-like kinase Plk1 and Cdk1 (Fig. 3B) (Lin et al. 2000; Wang et al. 2003), whereas GRASP55 is mitotically phosphorylated by ERK2 and Cdk1 (Jesch et al. 2001a; Xiang and Wang 2010).

\section{Partitioning the Golgi into the Daughter Cells}

Once disassembled, the mitotic Golgi membranes are present in at least two pools. In addition to vesicles that are evenly dispersed throughout the cytoplasm (Jesch et al. 2001b; Axelsson and Warren 2004), a significant portion of the mitotic Golgi membranes 
concentrate at the spindle poles and associate with astral microtubules (Fig. 1C, metaphase; Fig. 2) (Shima et al. 1998; Jokitalo et al. 2001; Seemann et al. 2002). These spindle-associated membranes are organized in clusters of tubulovesicular structures with a relatively constant number within each cell. The mitotic clusters are polarized, with cis-Golgi proteins spatially separated from those of the trans-Golgi (Shima et al. 1997), a similar pattern to that of the Golgi stacks during interphase. The spindle association of the mitotic Golgi clusters, which is also prominent in cells with monoasters (Fig. 1F), has prompted the idea that Golgi partitioning is regulated by the spindle (Shorter and Warren 2002). This has been tested by inducing asymmetrical cell division to segregate the entire spindle into only one of the daughter cells (Wei and Seemann 2009a). Upon division, both daughter cells assemble functional Golgi stacks, but the ribbon of interconnected stacks are only observed in the daughter cell that receives mitotic Golgi clusters partitioned together with the spindle. This indicates that the spindle plays a vital role in partitioning an intact Golgi ribbon (Wei and Seemann 2009c).

\section{Postmitotic Golgi Reassembly}

Upon segregation into the nascent daughter cells, the mitotic Golgi membranes reassemble during telophase and cytokinesis into two distinct ribbons on opposite sides of the nucleus (Fig. 1E, cytokinesis; Fig. 2). A smaller Golgi ribbon reforms adjacent to the midbody, whereas a larger ribbon is found in the pericentriolar region on the side away from the cleavage furrow (Shima et al. 1998; Bartz et al. 2008). The function of the smaller ribbon is not clear, but its positioning next to the midbody may facilitate an efficient and polarized delivery of membranes into the cleavage furrow to seal the plasma membrane during abscission. Consistent with this idea, it has been observed that Golgi-derived vesicles are directly delivered from both daughter cells into the cleavage furrow where these membranes fuse (Goss and Toomre 2008). Following abscission, the smaller ribbon moves to the opposite side of the nucleus and merges with the larger Golgi into a continuous ribbon (Gaietta et al. 2006).

Mechanistically, the Golgi is reformed at the end of mitosis by two interrelated processes, formation of flattened cisternae by membrane fusion and stacking of cisternae. Postmitotic Golgi membrane fusion is mediated by two AAA-ATPases, the N-ethylmaleimide-sensitive factor (NSF) and the valosin-containing protein (VCP)/p97 (Cdc48 in yeast) (Fig. 3D) (Acharya et al. 1995; Rabouille et al. 1995; Kondo et al. 1997). Stacking of Golgi cisternae requires the tethering factor $\mathrm{p} 115$ that initially links adjacent membranes (Shorter and Warren 1999) and the GRASP proteins that hold the cisternae into stacks (Fig. 3E) (Barr et al. 1998; Shorter et al. 1999).

\section{Two Membrane Fusion Pathways and Cisternal Formation}

Like most intracellular membrane fusion processes, postmitotic Golgi membrane fusion requires SNARE proteins. The assembly of SNARE proteins on opposite membranes into a SNAREpin complex leads to membrane fusion (Rothman and Warren 1994; Weber et al. 1998). Once the membranes are fused, the SNAREpin complex is then disassembled by NSF, which allows the next round of SNAREpin assembly and membrane fusion. Purified NSF, together with its cofactors $\alpha$ - and $\gamma$-SNAP (soluble NSF attachment protein), and the tethering factor p115 are sufficient for in vitro reassembly of mitotic Golgi membranes into cisternae (Rabouille et al. 1995; Tang et al. 2008, 2010a). However, although the ATPase activity of NSF is required for SNARE disassembly and sustained membrane fusion in most membrane fusion events, this activity is not required for postmitotic Golgi membrane fusion, suggesting a different role for NSF in Golgi reassembly (Muller et al. 1999). In telophase, dephosphorylation of GM130 (Lowe et al. 2000) allows the reformation of the giantin-p115-GM130 tethers (Fig. 3D). This reassociation may contribute to membrane fusion and cisternal formation (Shorter and Warren 1999) and is regulated by a Rab-GTPase (Shorter et al. 2002). 
Y. Wang and J. Seemann

Compared to NSF-dependent membrane fusion, p97-mediated cisternal regrowth is less well understood (Fig. 3D). Treatment of mitotic Golgi membranes with purified p97 and its cofactor p47 generates long, single cisternae (Rabouille et al. 1995; Kondo et al. 1997), indicating that p97/p47 drives homotypic membrane fusion. Furthermore, p97 can bind another adaptor protein, p37, and the p97/ p37 complex also promotes Golgi membrane fusion in vitro. Unlike the p97/p47 complex, however, the p97/p37 membrane fusion activity depends on p115 (Uchiyama et al. 2006). Although NSF- and p97-mediated Golgi reassembly share common components of SNARE proteins, these two pathways contribute nonadditively to cisternal regrowth (Rabouille et al. 1998). This suggests that they may have distinct roles in postmitotic Golgi membrane fusion, but the coordination between two pathways has not been fully elucidated.

The activity of the $\mathrm{p} 97 / \mathrm{p} 47$ complex in postmitotic Golgi reassembly depends on ubiquitin (Meyer 2005). Although p97 and ubiquitination are often associated with protein degradation, the membrane fusion activity of p97 does not involve the proteasome (Meyer et al. 2002; Wang et al. 2004). p47 binds monoubiquitin through its ubiquitin-associated (UBA) domain (Meyer et al. 2002). Deletion of the UBA domain of $\mathrm{p} 47$ or adding a mutant ubiquitin that does not bind to $\mathrm{p} 47$ suppresses p97/p47-mediated postmitotic fusion of Golgi membranes in vitro (Meyer et al. 2002; Wang et al. 2004). Furthermore, the p97/p47 membrane fusion process requires the activity of the deubiquitinating enzyme VCIP135 to remove ubiquitin moieties that were added during mitotic disassembly (Uchiyama et al. 2002; Wang et al. 2004). Full understanding of the underlying mechanism, however, requires the identification of the ubiquitin ligase and the substrate(s) on the Golgi membranes.

\section{Cisternal Stacking}

In telophase, cisternae start to reform by NSFand p97-mediated membrane fusion and begin to align with each other into stacks. The tethering factor p115 is required not only for NSF- and p97/p37-dependent cisternal formation, but also for initial stack formation (Shorter and Warren 1999). However, p115 is only temporarily required in the early steps of stacking. Following formation of the initial connections, stacking of the newly formed cisternae relies on the stacking proteins GRASP65 and GRASP55 (Fig. 3E). Both GRASPs are dephosphorylated at the end of mitosis, which restores their capability of oligomerization and thus allows cisternal restacking (Wang et al. 2003, 2005; Tang et al. 2010b). PP2A has been identified as the phosphatase that reverses phosphorylation of GRASP65 (Tang et al. 2008), but whether the same enzyme is responsible for GRASP55 dephosphorylation remains to be tested. Because GRASP65 and GRASP55 are localized on different parts of the Golgi (Shorter et al. 1999), these proteins may play essential roles in generation of the polarized, stacked structure (Xiang and Wang 2010).

\section{CONCLUDING REMARKS}

Despite recent advances, the mechanisms that regulate Golgi biogenesis remain largely mysterious. In particular, the interplay between the Golgi membranes and the mitotic machinery in the partitioning process must be further investigated at the mechanistic level. There are also only hints as to why the Golgi undergoes such extensive disassembly and reassembly during mammalian cell division and how this process regulates cell cycle progression. In addition, identification of the ubiquitin ligase and the substrates on the Golgi membranes will advance our understanding of $\mathrm{p} 97 / \mathrm{p} 47$-mediated postmitotic Golgi membrane fusion.

\section{ACKNOWLEDGMENTS}

We thank Yi Xiang, Danming Tang, and other members of the Wang Laboratory for suggestions and Jen-Hsuan Wei for confocal images and critical reading of the manuscript. Y.W. is supported by the Pardee Cancer Research Foundation, the National Institute of Health (GM087364), American Cancer Society 
(RGS-09-278-01-CSM), a University of Michigan Rackham Faculty Research Grant, the NIHfunded Michigan Alzheimer's Disease Research Center (P50 AG08761), and an anonymous donation. J.S. is supported by a grant from the NIH (GM096070). The authors declare no conflicts of interest.

\section{REFERENCES}

Acharya U, Jacobs R, Peters JM, Watson N, Farquhar MG Malhotra V. 1995. The formation of Golgi stacks from vesiculated Golgi membranes requires two distinct fusion events. Cell 82: 895-904.

Acharya U, Mallabiabarrena A, Acharya JK, Malhotra V. 1998. Signaling via mitogen-activated protein kinase kinase (MEK1) is required for Golgi fragmentation during mitosis. Cell 92: 183-192.

Axelsson MA, Warren G. 2004. Rapid, ER-independent diffusion of the mitotic Golgi haze. Mol Biol Cell 15: $1843-1852$.

Bailly E, McCaffrey M, Touchot N, Zahraoui A, Goud B, Bornens M. 1991. Phosphorylation of two small GTPbinding proteins of the Rab family by $\mathrm{p} 34 \mathrm{cdc} 2$. Nature 350: 715-718.

Barr FA, Nakamura N, Warren G. 1998. Mapping the interaction between GRASP 65 and GM130, components of a protein complex involved in the stacking of Golgi cisternae. EMBO J 17: 3258-3268.

Bartz R, Sun LP, Bisel B, Wei JH, Seemann J. 2008. Spatial separation of Golgi and ER during mitosis protects SREBP from unregulated activation. EMBO J 27: $948-$ 955.

Beard M, Satoh A, Shorter J, Warren G. 2005. A cryptic Rab1-binding site in the p115 tethering protein. J Biol Chem 280: 25840-25848.

Bonfanti L, Mironov AA Jr, Martinez-Menarguez JA, Martella O, Fusella A, Baldassarre M, Buccione R, Geuze HJ, Mironov AA, Luini A. 1998. Procollagen traverses the Golgi stack without leaving the lumen of cisternae: Evidence for cisternal maturation. Cell 95: 993-1003.

Colanzi A, Corda D. 2007. Mitosis controls the Golgi and the Golgi controls mitosis. Curr Opin Cell Biol 19: 386-393.

Colanzi A, Deerinck TJ, Ellisman MH, Malhotra V. 2000. A specific activation of the mitogen-activated protein kinase kinase 1 (MEK1) is required for Golgi fragmentation during mitosis. J Cell Biol 149: 331-339.

Colanzi A, Carcedo CH, Persico A, Cericola C, Turacchio G Bonazzi M, Luini A, Corda D. 2007. The Golgi mitotic checkpoint is controlled by BARS-dependent fission of the Golgi ribbon into separate stacks in G2. EMBO J 26: $2465-2476$.

Dacks JB, Davis LA, Sjogren AM, Andersson JO, Roger AJ, Doolittle WF. 2003. Evidence for Golgi bodies in proposed "Golgi-lacking" lineages. Proc Biol Sci 270 (Suppl. 2): S168-S171.

Diao A, Frost L, Morohashi Y, Lowe M. 2008. Coordination of golgin tethering and SNARE assembly: GM130 binds syntaxin 5 in a p115-regulated manner. $J$ Biol Chem 283: 6957-6967.

Duran JM, Kinseth M, Bossard C, Rose DW, Polishchuk R, Wu CC, Yates J, Zimmerman T, Malhotra V. 2008. The role of GRASP55 in Golgi fragmentation and entry of cells into mitosis. Mol Biol Cell 19: 2579-2587.

Elsner M, Hashimoto H, Nilsson T. 2003. Cisternal maturation and vesicle transport: Join the band wagon! Mol Membr Biol 20: 221-229.

Emr S, Glick BS, Linstedt AD, Lippincott-Schwartz J, Luini A, Malhotra V, Marsh BJ, Nakano A, Pfeffer SR, Rabouille C, et al. 2009. Journeys through the Golgi-Taking stock in a new era. J Cell Biol 187: 449-453.

Feinstein TN, Linstedt AD. 2007. Mitogen-activated protein kinase kinase 1-dependent Golgi unlinking occurs in G2 phase and promotes the G2/M cell cycle transition. $\mathrm{Mol}$ Biol Cell 18: 594-604.

Feinstein TN, Linstedt AD. 2008. GRASP55 regulates Golgi ribbon formation. Mol Biol Cell 19: 2696-2707.

Franzusoff A, Redding K, Crosby J, Fuller RS, Schekman R. 1991. Localization of components involved in protein transport and processing through the yeast Golgi apparatus. J Cell Biol 112: 27-37.

Gaietta GM, Giepmans BN, Deerinck TJ, Smith WB, Ngan L, Llopis J, Adams SR, Tsien RY, Ellisman MH. 2006. Golgi twins in late mitosis revealed by genetically encoded tags for live cell imaging and correlated electron microscopy. Proc Natl Acad Sci 103: 17777-17782.

Glick BS, Nakano A. 2009. Membrane traffic within the Golgi apparatus. Annu Rev Cell Dev Biol 25: 113-132.

Goldfischer S. 1982. The internal reticular apparatus of Camillo Golgi: A complex, heterogeneous organelle, enriched in acid, neutral, and alkaline phosphatases, and involved in glycosylation, secretion, membrane flow, lysosome formation, and intracellular digestion. J Histochem Cytochem 30: 717-733.

Goss JW, Toomre DK. 2008. Both daughter cells traffic and exocytose membrane at the cleavage furrow during mammalian cytokinesis. J Cell Biol 181: 1047-1054.

Gromley A, Yeaman C, Rosa J, Redick S, Chen CT, Mirabelle S, Guha M, Sillibourne J, Doxsey SJ. 2005. Centriolin anchoring of exocyst and SNARE complexes at the midbody is required for secretory-vesicle-mediated abscission. Cell 123: 75-87.

Hager KM, Striepen B, Tilney LG, Roos DS. 1999. The nuclear envelope serves as an intermediary between the ER and Golgi complex in the intracellular parasite Toxoplasma gondii. J Cell Sci 112: 2631-2638.

He CY, Ho HH, Malsam J, Chalouni C, West CM, Ullu E, Toomre D, Warren G. 2004. Golgi duplication in Trypanosoma brucei. J Cell Biol 165: 313-321.

Henderson GP, Gan L, Jensen GJ. 2007. 3-D ultrastructure of O. tauri: Electron cryotomography of an entire eukaryotic cell. PLoS One 2: e749.

Hidalgo Carcedo C, Bonazzi M, Spano S, Turacchio G, Colanzi A, Luini A, Corda D. 2004. Mitotic Golgi partitioning is driven by the membrane-fissioning protein CtBP3/BARS. Science 305: 93-96.

Jaffe AB, Hall A. 2005. Rho GTPases: Biochemistry and biology. Annu Rev Cell Dev Biol 21: 247-269. 
Y. Wang and J. Seemann

Jesch SA, Lewis TS, Ahn NG, Linstedt AD. 2001a. Mitotic phosphorylation of Golgi reassembly stacking protein 55 by mitogen-activated protein kinase ERK2. Mol Biol Cell 12: 1811-1817.

Jesch SA, Mehta AJ, Velliste M, Murphy RF, Linstedt AD. 2001b. Mitotic Golgi is in a dynamic equilibrium between clustered and free vesicles independent of the ER. Traffic 2: 873-884.

Jokitalo E, Cabrera-Poch N, Warren G, Shima DT. 2001. Golgi clusters and vesicles mediate mitotic inheritance independently of the endoplasmic reticulum. J Cell Biol 154: $317-330$.

Kano F, Takenaka K, Yamamoto A, Nagayama K, Nishida E, Murata M. 2000. MEK and Cdc2 kinase are sequentially required for Golgi disassembly in MDCK cells by the mitotic Xenopus extracts. J Cell Biol 149: 357-368.

Klute MJ, Melançon P, Dacks JB. 2011. Evolution and diversity of the Golgi apparatus. Cold Spring Harb Perspect Biol 3: a007849.

Kondo H, Rabouille C, Newman R, Levine TP, Pappin D, Freemont P, Warren G. 1997. p47 is a cofactor for p97-mediated membrane fusion. Nature 388: 75-78.

Kornfeld R, Kornfeld S. 1985. Assembly of asparagine-linked oligosaccharides. Ann Rev Biochem 54: 631-664.

Levine TP, Rabouille C, Kieckbusch RH, Warren G. 1996. Binding of the vesicle docking protein p115 to Golgi membranes is inhibited under mitotic conditions. $J$ Biol Chem 271: 17304-17311.

Lin CY, Madsen ML, Yarm FR, Jang YJ, Liu X, Erikson RL. 2000. Peripheral Golgi protein GRASP65 is a target of mitotic polo-like kinase (Plk) and Cdc2. Proc Natl Acad Sci 97: 12589-12594.

Linstedt AD. 1999. Stacking the cisternae. Curr Biol 9: R893-R896.

Litvak V, Argov R, Dahan N, Ramachandran S, Amarilio R, Shainskaya A, Lev S. 2004. Mitotic phosphorylation of the peripheral Golgi protein Nir2 by Cdk1 provides a docking mechanism for Plk1 and affects cytokinesis completion. Mol Cell 14: 319-330.

Lopez-Sanchez I, Sanz-Garcia M, Lazo PA. 2009. Plk3 interacts with and specifically phosphorylates VRK1 in Ser342, a downstream target in a pathway that induces Golgi fragmentation. Mol Cell Biol 29: 1189-1201.

Losev E, Reinke CA, Jellen J, Strongin DE, Bevis BJ, Glick BS. 2006. Golgi maturation visualized in living yeast. Nature 441: 1002-1006.

Lowe M, Barr FA. 2007. Inheritance and biogenesis of organelles in the secretory pathway. Nat Rev Mol Cell Biol 8: 429-439.

Lowe M, Nakamura N, Warren G. 1998a. Golgi division and membrane traffic. Trends Cell Biol 8: 40-44.

Lowe M, Rabouille C, Nakamura N, Watson R, Jackman M, Jamsa E, Rahman D, Pappin DJ, Warren G. 1998b. Cdc2 kinase directly phosphorylates the cis-Golgi matrix protein GM130 and is required for Golgi fragmentation in mitosis. Cell 94: 783-793.

Lowe M, Gonatas NK, Warren G. 2000. The mitotic phosphorylation cycle of the cis-Golgi matrix protein GM130. J Cell Biol 149: 341-356.
Lucocq JM, Berger EG, Warren G. 1989. Mitotic Golgi fragments in HeLa cells and their role in the reassembly pathway. J Cell Biol 109: 463-474.

Lupashin V, Sztul E. 2005. Golgi tethering factors. Biochim Biophys Acta 1744: 325-339.

Matsuura-Tokita K, Takeuchi M, Ichihara A, Mikuriya K, Nakano A. 2006. Live imaging of yeast Golgi cisternal maturation. Nature 441: 1007-1010.

Meyer HH. 2005. Golgi reassembly after mitosis: The AAA family meets the ubiquitin family. Biochim Biophys Acta 1744: 481-492.

Meyer HH, Wang Y, Warren G. 2002. Direct binding of ubiquitin conjugates by the mammalian p97 adaptor complexes, p47 and Ufd1-Np14. EMBO J 21: 5645-5652.

Miller PM, Folkmann AW, Maia AR, Efimova N, Efimov A, Kaverina I. 2009. Golgi-derived CLASP-dependent microtubules control Golgi organization and polarized trafficking in motile cells. Nat Cell Biol 11: 1069-1080.

Misteli T, Warren G. 1994. COP-coated vesicles are involved in the mitotic fragmentation of Golgi stacks in a cell-free system. J Cell Biol 125: 269-282.

Misteli T, Warren G. 1995. A role for tubular networks and a COP I-independent pathway in the mitotic fragmentation of Golgi stacks in a cell-free system. J Cell Biol 130: 1027-1039.

Mowbrey K, Dacks JB. 2009. Evolution and diversity of the Golgi body. FEBS Lett 583: 3738-3745.

Moyer BD, Allan BB, Balch WE. 2001. Rab1 interaction with a GM130 effector complex regulates COPII vesicle cisGolgi tethering. Traffic 2: 268-276.

Muller JM, Rabouille C, Newman R, Shorter J, Freemont P, Schiavo G, Warren G, Shima DT. 1999. An NSF function distinct from ATPase-dependent SNARE disassembly is essential for Golgi membrane fusion. Nat Cell Biolog 1: 335-340.

Nakamura N. 2010. Emerging new roles of GM130, a cisGolgi matrix protein, in higher order cell functions. $J$ Pharmacol Sci 112: 255-264.

Nakamura N, Lowe M, Levine TP, Rabouille C, Warren G. 1997. The vesicle docking protein p115 binds GM130, a cis-Golgi matrix protein, in a mitotically regulated manner. Cell 89: 445-455.

Novick P, Ferro S, Schekman R. 1981. Order of events in the yeast secretory pathway. Cell 25: 461-469.

Orci L, Stamnes M, Ravazzola M, Amherdt M, Perrelet A, Sollner TH, Rothman JE. 1997. Bidirectional transport by distinct populations of COPI-coated vesicles. Cell 90: $335-349$.

Patterson GH, Hirschberg K, Polishchuk RS, Gerlich D, Phair RD, Lippincott-Schwartz J. 2008. Transport through the Golgi apparatus by rapid partitioning within a two-phase membrane system. Cell 133: 1055-1067.

Pelletier L, Stern CA, Pypaert M, Sheff D, Ngo HM, Roper N, He CY, Hu K, Toomre D, Coppens I, et al. 2002. Golgi biogenesis in Toxoplasma gondii. Nature 418: 548-552.

Persico A, Cervigni RI, Barretta ML, Corda D, Colanzi A. 2010. Golgi partitioning controls mitotic entry through Aurora-a kinase. Mol Biol Cell 21: 3708-3721.

Preisinger C, Korner R, Wind M, Lehmann WD, Kopajtich R, Barr FA. 2005. Plk1 docking to GRASP65 
phosphorylated by Cdk1 suggests a mechanism for Golgi checkpoint signalling. EMBO J 24: 753-765.

Preuss D, Mulholland J, Franzusoff A, Segev N, Botstein D. 1992. Characterization of the Saccharomyces Golgi complex through the cell cycle by immunoelectron microscopy. Mol Biol Cell 3: 789-803.

Puthenveedu MA, Bachert C, Puri S, Lanni F, Linstedt AD. 2006. GM130 and GRASP65-dependent lateral cisternal fusion allows uniform Golgi-enzyme distribution. Nat Cell Biol 8: $238-248$.

Rabouille C, Levine TP, Peters JM, Warren G. 1995. An NSFlike ATPase, p97, and NSF mediate cisternal regrowth from mitotic Golgi fragments. Cell 82: 905-914.

Rabouille C, Kondo H, Newman R, Hui N, Freemont P, Warren G. 1998. Syntaxin 5 is a common component of the NSF- and p97-mediated reassembly pathways of Golgi cisternae from mitotic Golgi fragments in vitro. Cell 92: 603-610.

Rambourg A, Clermont Y, Hermo L, Segretain D. 1987. Tridimensional structure of the Golgi apparatus of nonciliated epithelial cells of the ductuli efferentes in rat: An electron microscope stereoscopic study. Biol Cell 60: $103-115$.

Rios RM, Bornens M. 2003. The Golgi apparatus at the cell centre. Curr Opin Cell Biol 15: 60-66.

Roth J. 2002. Protein N-glycosylation along the secretory pathway: Relationship to organelle topography and function, protein quality control, and cell interactions. Chem Rev 102: 285-303.

Rothman JE, Warren G. 1994. Implications of the SNARE hypothesis for intracellular membrane topology and dynamics. Curr Biol 4: 220-233.

Seemann J, Pypaert M, Taguchi T, Malsam J, Warren G 2002. Partitioning of the matrix fraction of the Golgi apparatus during mitosis in animal cells. Science 295: 848-851.

Shaul YD, Seger R. 2006. ERK1c regulates Golgi fragmentation during mitosis. J Cell Biol 172: 885-897.

Shima DT, Haldar K, Pepperkok R, Watson R, Warren G. 1997. Partitioning of the Golgi apparatus during mitosis in living HeLa cells. J Cell Biol 137: 1211-1228.

Shima DT, Cabrera-Poch N, Pepperkok R, Warren G. 1998. An ordered inheritance strategy for the Golgi apparatus: Visualization of mitotic disassembly reveals a role for the mitotic spindle. J Cell Biol 141: 955-966.

Shorter J, Warren G. 1999. A role for the vesicle tethering protein, p115, in the post-mitotic stacking of reassembling Golgi cisternae in a cell-free system. J Cell Biol 146: $57-70$.

Shorter J, Warren G. 2002. Golgi architecture and inheritance. Annu Rev Cell Dev Biol 18: 379-420.

Shorter J, Watson R, Giannakou ME, Clarke M, Warren G, Barr FA. 1999. GRASP55, a second mammalian GRASP protein involved in the stacking of Golgi cisternae in a cell-free system. ЕMBO J 18: 4949-4960.

Shorter J, Beard MB, Seemann J, Dirac-Svejstrup AB, Warren G. 2002. Sequential tethering of Golgins and catalysis of SNAREpin assembly by the vesicle-tethering protein p115. J Cell Biol 157: 45-62.
Sonnichsen B, Lowe M, Levine T, Jamsa E, Dirac-Svejstrup B, Warren G. 1998. A role for giantin in docking COPI vesicles to Golgi membranes. J Cell Biol 140: 1013-1021.

Sutterlin C, Lin CY, Feng Y, Ferris DK, Erikson RL, Malhotra V. 2001. Polo-like kinase is required for the fragmentation of pericentriolar Golgi stacks during mitosis. Proc Natl Acad Sci 98: 9128-9132.

Sutterlin C, Hsu P, Mallabiabarrena A, Malhotra V. 2002. Fragmentation and dispersal of the pericentriolar Golgi complex is required for entry into mitosis in mammalian cells. Cell 109: 359-369.

Tang D, Mar K, Warren G, Wang Y. 2008. Molecular mechanism of mitotic Golgi disassembly and reassembly revealed by a defined reconstitution assay. J Biol Chem 283: 6085-6094.

Tang D, Xiang Y, Wang Y. 2010a. Reconstitution of the cell cycle regulated Golgi disassembly and reassembly in a cell free system. Nature Protocols 5: 758-772.

Tang D, Yuan H, Wang Y. 2010b. The role of GRASP65 in Golgi cisternal stacking and cell cycle progression. Traffic 11: $827-842$.

Trucco A, Polishchuk RS, Martella O, Di Pentima A, Fusella A, Di Giandomenico D, San Pietro E, Beznoussenko GV, Polishchuk EV, Baldassarre M, et al. 2004. Secretory traffic triggers the formation of tubular continuities across Golgi sub-compartments. Nat Cell Biol 6: 1071-1081.

Uchiyama K, Jokitalo E, Kano F, Murata M, Zhang X, Canas B, Newman R, Rabouille C, Pappin D, Freemont P, et al. 2002. VCIP135, a novel essential factor for $\mathrm{p} 97 / \mathrm{p} 47$ mediated membrane fusion, is required for Golgi and ER assembly in vivo. J Cell Biol 159: 855-866.

Uchiyama K, Jokitalo E, Lindman M, Jackman M, Kano F, Murata M, Zhang X, Kondo H. 2003. The localization and phosphorylation of p47 are important for Golgi disassembly-assembly during the cell cycle. J Cell Biol 161: $1067-1079$.

Uchiyama K, Totsukawa G, Puhka M, Kaneko Y, Jokitalo E, Dreveny I, Beuron F, Zhang X, Freemont P, Kondo H. 2006. p37 is a p97 adaptor required for Golgi and ER biogenesis in interphase and at the end of mitosis. Dev Cell 11: $803-816$.

Varki A. 1998. Factors controlling the glycosylation potential of the Golgi apparatus. Trends Cell Biol 8: 34-40.

Wang Y. 2008. Golgi apparatus inheritance. In The Golgi apparatus: State of the art 110 years after Camillo Golgi's discovery (ed. Mironov A et al.), pp. 580-607. SpringerVerlag, New York.

Wang Y, Seemann J, Pypaert M, Shorter J, Warren G. 2003. A direct role for GRASP65 as a mitotically regulated Golgi stacking factor. $E M B O J$ 22: 3279-3290.

Wang Y, Satoh A, Warren G, Meyer HH. 2004. VCIP135 acts as a deubiquitinating enzyme during p97-p47-mediated reassembly of mitotic Golgi fragments. J Cell Biol 164: 973-978.

Wang Y, Satoh A, Warren G. 2005. Mapping the functional domains of the Golgi stacking factor GRASP65. J Biol Chem 280: 4921-4928.

Wang Y, Wei JH, Bisel B, Tang D, Seemann J. 2008. Golgi cisternal unstacking stimulates COPI vesicle budding and protein transport. PLoS ONE 3: e1647. 
Y. Wang and J. Seemann

Warren G. 1993. Membrane partitioning during cell division. Annu Rev Biochem 62: 323-348.

Weber T, Zemelman BV, McNew JA, Westermann B, Gmachl M, Parlati F, Sollner TH, Rothman JE. 1998. SNAREpins: Minimal machinery for membrane fusion. Cell 92: 759-772.

Wei JH, Seemann J. 2009a. Induction of asymmetrical cell division to analyze spindle-dependent organelle partitioning using correlative microscopy techniques. Nat Protoc 4: 1653-1662.

Wei JH, Seemann J. 2009b. Mitotic division of the mammalian Golgi apparatus. Semin Cell Dev Biol 20: 810-816.

Wei JH, Seemann J. 2009c. The mitotic spindle mediates inheritance of the Golgi ribbon structure. J Cell Biol 184: 391-397.

Wei JH, Seemann J. 2010. Unraveling the Golgi ribbon. Traffic 11: 1391-1400.

Weide T, Bayer M, Koster M, Siebrasse JP, Peters R, Barnekow A. 2001. The Golgi matrix protein GM130: A specific interacting partner of the small GTPase rablb. $E M B O$ Rep 2: 336-341.

Weinberger A, Kamena F, Kama R, Spang A, Gerst JE. 2005. Control of Golgi morphology and function by Sed $5 \mathrm{t}$ SNARE phosphorylation. Mol Biol Cell 16: 4918-4930.

Xiang Y, Wang Y. 2010. GRASP55 and GRASP65 play complementary and essential roles in Golgi cisternal stacking. J Cell Biol 188: 237-251.

Xiang Y, Seemann J, Bisel B, Punthambaker S, Wang Y. 2007. Active ADP-ribosylation factor-1 (ARF1) is required for mitotic Golgi fragmentation. J Biol Chem 282: 2182921837.

Xie S, Wang Q, Ruan Q, Liu T, Jhanwar-Uniyal M, Guan K, Dai W. 2004. MEK1-induced Golgi dynamics during cell cycle progression is partly mediated by Polo-like kinase-3. Oncogene 23: 3822-3829.

Yoshimura S, Yoshioka K, Barr FA, Lowe M, Nakayama K, Ohkuma S, Nakamura N. 2005. Convergence of cell cycle regulation and growth factor signals on GRASP65. J Biol Chem 280: 23048-23056. 


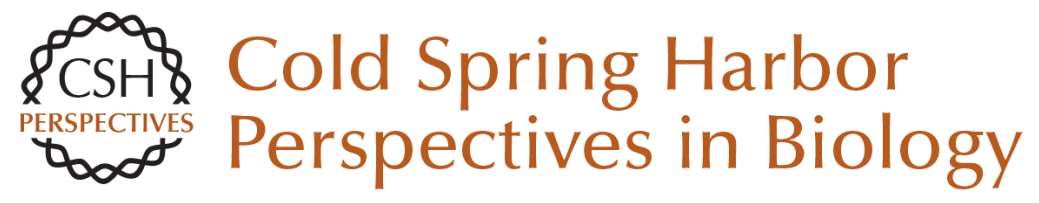

\section{Golgi Biogenesis}

Yanzhuang Wang and Joachim Seemann

Cold Spring Harb Perspect Biol 2011; doi: 10.1101/cshperspect.a005330 originally published online June 20, 2011

\section{Subject Collection The Golgi}

Structure of Golgi Transport Proteins

Daniel Kümmel and Karin M. Reinisch

\section{Golgi Biogenesis}

Yanzhuang Wang and Joachim Seemann

Golgi Glycosylation and Human Inherited

Diseases

Hudson H. Freeze and Bobby G. Ng

Models for Golgi Traffic: A Critical Assessment Benjamin S. Glick and Alberto Luini

\section{Architecture of the Mammalian Golgi} Judith Klumperman

Evolution and Diversity of the Golgi Mary J. Klute, Paul Melançon and Joel B. Dacks

Evolutionary Forces Shaping the Golgi

Glycosylation Machinery: Why Cell Surface

Glycans Are Universal to Living Cells Ajit Varki

Golgi Positioning

Smita Yadav and Adam D. Linstedt
Golgi and Related Vesicle Proteomics: Simplify to Identify Joan Gannon, John J.M. Bergeron and Tommy Nilsson

Organization of SNAREs within the Golgi Stack Jörg Malsam and Thomas H. Söllner

Golgi during Development Weimin Zhong

Entry and Exit Mechanisms at the cis-Face of the Golgi Complex Andrés Lorente-Rodríguez and Charles Barlowe

COPI Budding within the Golgi Stack Vincent Popoff, Frank Adolf, Britta Brügger, et al.

Mechanisms of Protein Retention in the Golgi David K. Banfield

The Golgin Coiled-Coil Proteins of the Golgi

Apparatus Sean Munro

Signaling at the Golgi Peter Mayinger

For additional articles in this collection, see http://cshperspectives.cshlp.org/cgi/collection/

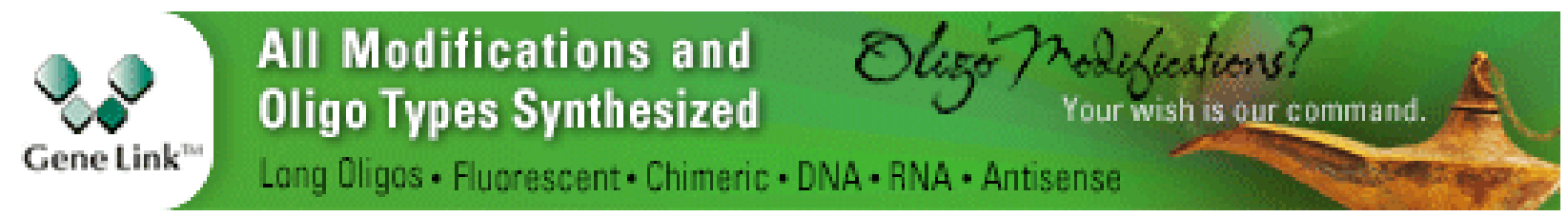

Copyright @ 2011 Cold Spring Harbor Laboratory Press; all rights reserved 